Research Journal of Applied Sciences 13 (12): 704-710, 2018

ISSN: $1815-932 \mathrm{X}$

(C) Medwell Journals, 2018

\title{
Biosorption of Reactive Black 5 in Binary Dye Mixture onto Sawdust of Parkia biglobosa
}

\author{
${ }^{1}$ Giwa Abdurrahim Adebisi, ${ }^{2}$ Aderibigbe Deborah Olubunmi, ${ }^{1}$ Wewers Francois and \\ ${ }^{2}$ Bello Isah Adewale, \\ ${ }^{1}$ Department of Pure and Applied Chemistry, Cape Peninsua University of Technology, \\ P.O. Box 1906, 7535 Bellville, South Africa \\ ${ }^{2}$ Department of Pure and Applied Chemistry, Ladoke Akintola University of Technology, \\ P.M.B 4000, Ogbomoso, Nigeria
}

\begin{abstract}
The development and modification of existing processes for the abatement of pollutants in the environment is a continuous exercise. In this regard, the importance of wastewater treatment before its eventual discharge into the environment cannot be overemphasized. Adsorption process has been widely accepted as an efficient method and research is ongoing on the possible application of agricultural residues as adsorbents in wastewater treatment. This study investigates the potential of Parkia biglobosa sawdust in removing reactive black 5 dye from aqueous solutions in single and binary dye systems. Several works have been conducted on the adsorption of reactive dyes but reports on their adsorption as a component of a mixture of dyes is scanty. The sawdust, collected from a local sawmill was thoroughly washed, dried and characterized using Fourier Transform-Infrared (FT-IR) spectrophotometer and Scanning Electron Microscope (SEM). Batch adsorption experiments were conducted to determine the effects of adsorbent dose, initial concentration and $\mathrm{pH}$ of the dye solution. Five isotherm models were employed in the interpretation of the equilibrium experiments. Kinetics and thermodynamics of the adsorption processes were also studied. The results indicate the presence of functional groups which could be potential adsorption sites for interaction with the dye on the sawdust. The kinetics of the adsorption in both single and binary systems could best be described by the pseudo-second order model and Langmuir gave the best fit for the equilibrium adsorption data $\left(\mathrm{R}^{2}>0.94\right)$. The maximum monolayer adsorption capacity of the adsorbent for the dye was low $(2.21 \mathrm{mg} / \mathrm{G})$ with no significant difference in the 2 systems. The adsorption processes in all the systems were spontaneous with $\Delta \mathrm{G}$ becoming increasingly more negative $(-0.15-2.81 \mathrm{~kJ} / \mathrm{mol})$ as temperature increases. The enthalpy change $(\Delta \mathrm{H})$ for the sorption in both systems was positive, indicating that the process was endothermic, the change in entropy $(\Delta S)$ was also positive an indication of increased disorderliness on the surface of the adsorbent.
\end{abstract}

Key words: Reactive black, binary dye system, adsorption isotherm, adsorption kinetics, sawdust, Parkia biglobosa

\section{INTRODUCTION}

Dyes usually have synthetic origin and complex aromatic molecular structures which make them more stable and more difficult to biodegrade (Eren and Acar, 2006). Dye producers and consumers are interested in the stability and fastness of dyes and consequently are producing dyestuffs which are more difficult to degrade after being used (Seey and Kassim, 2012). There are more than 10,000 commercially available dyes with over $7 \times 10^{5}$ ton of dyestuff being produced annually across the world (Eren and Acar, 2006).
Textile, cosmetics, food, rubber, leather, pharmaceutical, paper and printing industries and dye houses, make use of dyes in their processes (Iscen et al., 2007). The total dye consumption of the textile industry worldwide is more than $10^{7} \mathrm{~kg} /$ year and about $90 \%$ ends on fabrics (Seey and Kassim, 2012). It is estimated that $10-15 \%$ of the dye is lost during the dyeing process and released with the effluent (Akceylan et al., 2009).

Reactive dyes are typically azo-based chromophores combined with different types of reactive groups (Eren and Acar, 2006). They differ from all other classes of

Corresponding Author: Bello Isah Adewale, Department of Pure and Applied Chemistry, Ladoke Akintola University of Technology, P.M.B 4000, Ogbomoso, Nigeria 
dyes in that they bind to the textile fibres such as cotton to form covalent bonds (Aksu and Tezer, 2000). However, nearly $50 \%$ of reactive dyes may be lost in the effluent after the dyeing of cellulose fibres and are highly recalcitrant to conventional wastewater treatment processes (Vijayaraghavan and Yun, 2007). They are also known to have low adsorbability on a wider range of adsorbents (Rachakornkij et al., 2004). In this study, the biosorption of reactive black 5 (also known as remazol black B) in binary mixture with a model ionic dye, congo red, onto the sawdust of Parkia biglobosa was investigated.

\section{MATERIALS AND METHODS}

Preparation and characterization of adsorbent: Sawdust of Parkia biglobosa (Locust bean tree) was collected from a local sawmill in Ogbomoso metropolis, Nigeria. It was sorted, washed with distilled water, drained, oven dried and sieved into different particle sizes. It was washed again several times with large quantities of distilled water, so as to ensure the removal of any soluble component that may interfere with adsorption process. It was then oven-dried at $105^{\circ} \mathrm{C}$ and stored as Sawdust (SD) adsorbent. SD was characterized using scanning electron microscope fourier transform infrared spectroscopy, X-ray diffraction and $\mathrm{pH}$ point of zero charge $\left(\mathrm{pH}_{\mathrm{zpc}}\right)$.
Preparation of adsorbate: The adsorbate consists of reactive black 5 (Color Index (C.I), $52015 ; \lambda_{\max }, 598 \mathrm{~nm}$; molecular weight, $\mathrm{M}$ and $\mathrm{B}$ laboratory chemicals) singly and in binary mixture with congo red (Color Index (C.I.), $22120 ; \lambda_{\text {max. }} 500 \mathrm{~nm}$; molecular weight, $696.66, \mathrm{M}$ and $\mathrm{B}$ laboratory chemicals). Stock solutions of the two dyes of concentration $1000 \mathrm{mg} / \mathrm{L}$ were prepared separately in distilled. Appropriate working solutions were prepared from the stock solutions by accurate dilution with distilled water. Experimental solutions of both single and binary dye mixture of desired concentrations were prepared by mixing appropriate volumes of the stock solutions and accurately diluting it with distilled water (Fig. 1).

Batch adsorption studies: Batch adsorption experiments were conducted to study the effects of SD dose, initial concentration and $\mathrm{pH}$ of the adsorbate (the dye) temperature and contact time. The isotherm, kinetics and thermodynamics of the process were also studied. These were carried out by shaking desired doses of the adsorbent with fixed volume of the dye solutions of the known initial concentration solution at predetermined temperature and contact time in a horizontal shaker (SM 101 by Surgafriend Medicals). The mixture was filtered and the residual concentration of the dye determined using UV-VIS scanning spectrophotometer, genesys 10 . Changes in the initial $\mathrm{pH}$ of the solutions were effected
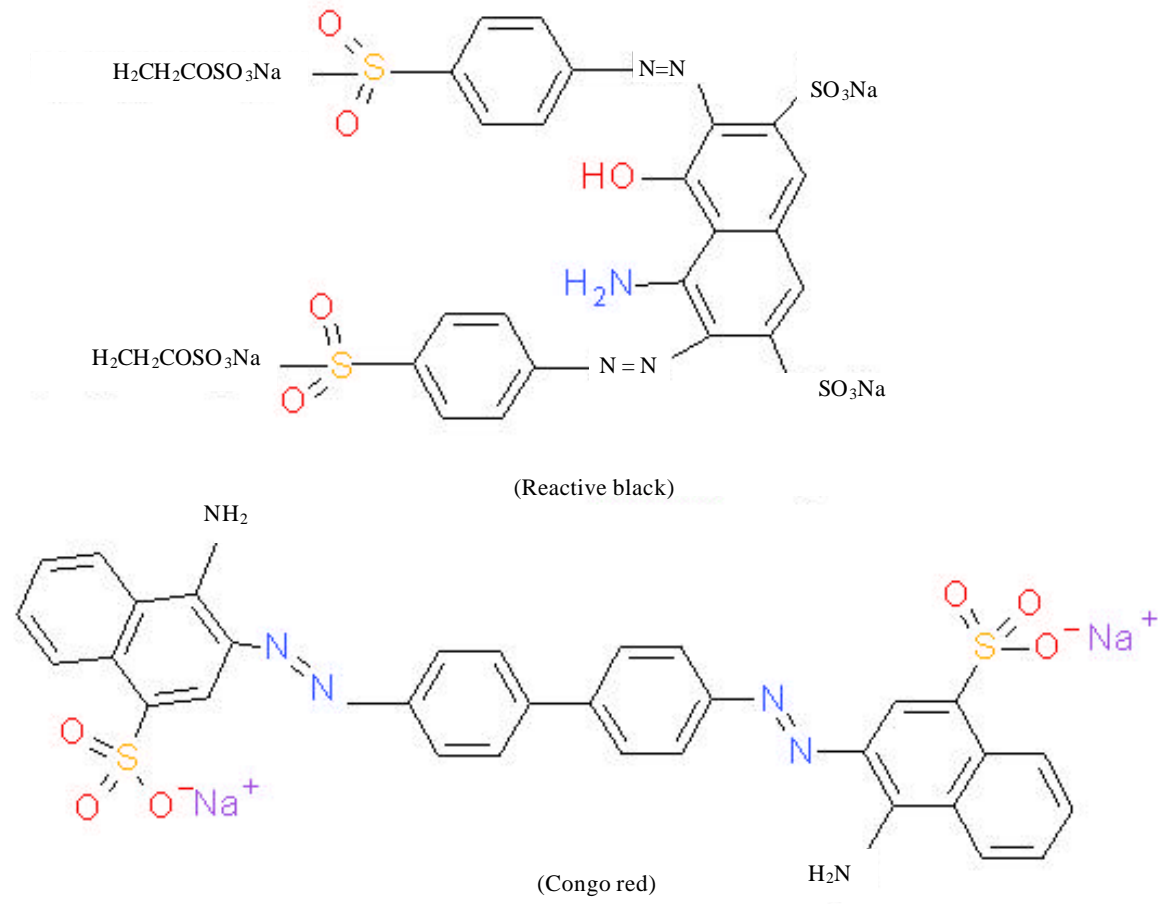

Fig. 1: Structural formula of reactive black and congo red 
with $0.1 \mathrm{M} \mathrm{HCl}$ or $0.1 \mathrm{M} \mathrm{NaOH}$ solutions to attain the desired $\mathrm{pH}$ values. The amount of dye removed was evaluated using the following Eq. 1 and 2:

$$
\begin{aligned}
& q_{e}=\frac{\left(c_{0}-c_{e}\right) v}{w} \\
& q_{t}=\frac{\left(c_{0}-c_{t}\right) v}{w}
\end{aligned}
$$

Where:

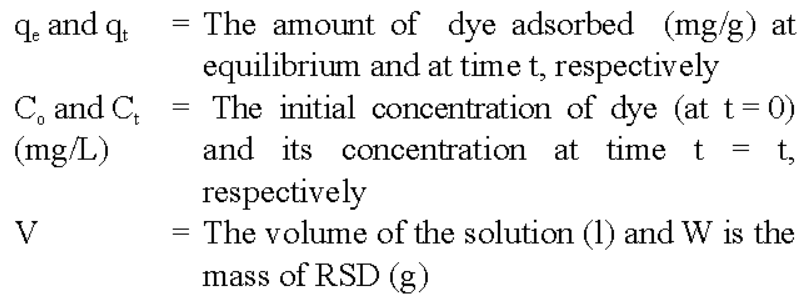

\section{RESULTS AND DISCUSSION}

Characterization of SD: The FTIR spectrum of SD is presented as Fig. 2. It shows some absorption peaks that revealed the complexity of the sawdust. There are 2 broad bands at 3417 and $3335 \mathrm{~cm}^{-1}$ representing bonded-OH of the oxygen-containing functional groups. The positions of the C-H (2918 and $\left.2937 \mathrm{~cm}^{-1}\right)$, aliphatic C-C $\left(1244 \mathrm{~cm}^{-1}\right)$, aromatic $\mathrm{C}=\mathrm{C}\left(1620 \mathrm{~cm}^{-1}\right)$ and carboxyl/carbonyl $\left(1735 \mathrm{~cm}^{-1}\right)$ vibrations also triple bond $\mathrm{C}=\mathrm{C} / \mathrm{C}=\mathrm{N}$ (2142 $\mathrm{cm}^{-1}$ ) contributed by those in the structure of cellulose, hemicellulose and lignin are indicated by the spectrum of SD. Thus, the FTIR analysis indicates that the $\mathrm{SD}$ is represented by functional groups such as $\mathrm{COOH}, \mathrm{C}=\mathrm{O}, \mathrm{C}=\mathrm{C}, \mathrm{C}=\mathrm{C}$ and $\mathrm{C}=\mathrm{N}$ that could be potential adsorption sites for interaction with the dye .

The surface textural structure of SD is presented as scanning electron micrograph Fig. 3 showing the rough texture and porous nature of the surface of the adsorbent. A rough surface is generally an indication of high surface area which enhances adsorption (Demirbas et al., 2004).

Effect of initial RB5 concentration on its adsorption: The effect of the initial concentration of RB5 dye on its adsorption by SD is shown in Fig. 4. Adsorption capacity $\left(\mathrm{q}_{\mathrm{e}}\right)$ increases with increasing initial concentration of RB5 dye. From the Fig. 3 an increase in the initial concentration of the RB5 dye from $10-100 \mathrm{mg} / \mathrm{L}$ led to an increase in adsorption capacity $\left(\mathrm{q}_{\mathrm{e}}\right)$ from $0.234-2.043 \mathrm{mg} / \mathrm{g}$. Similar

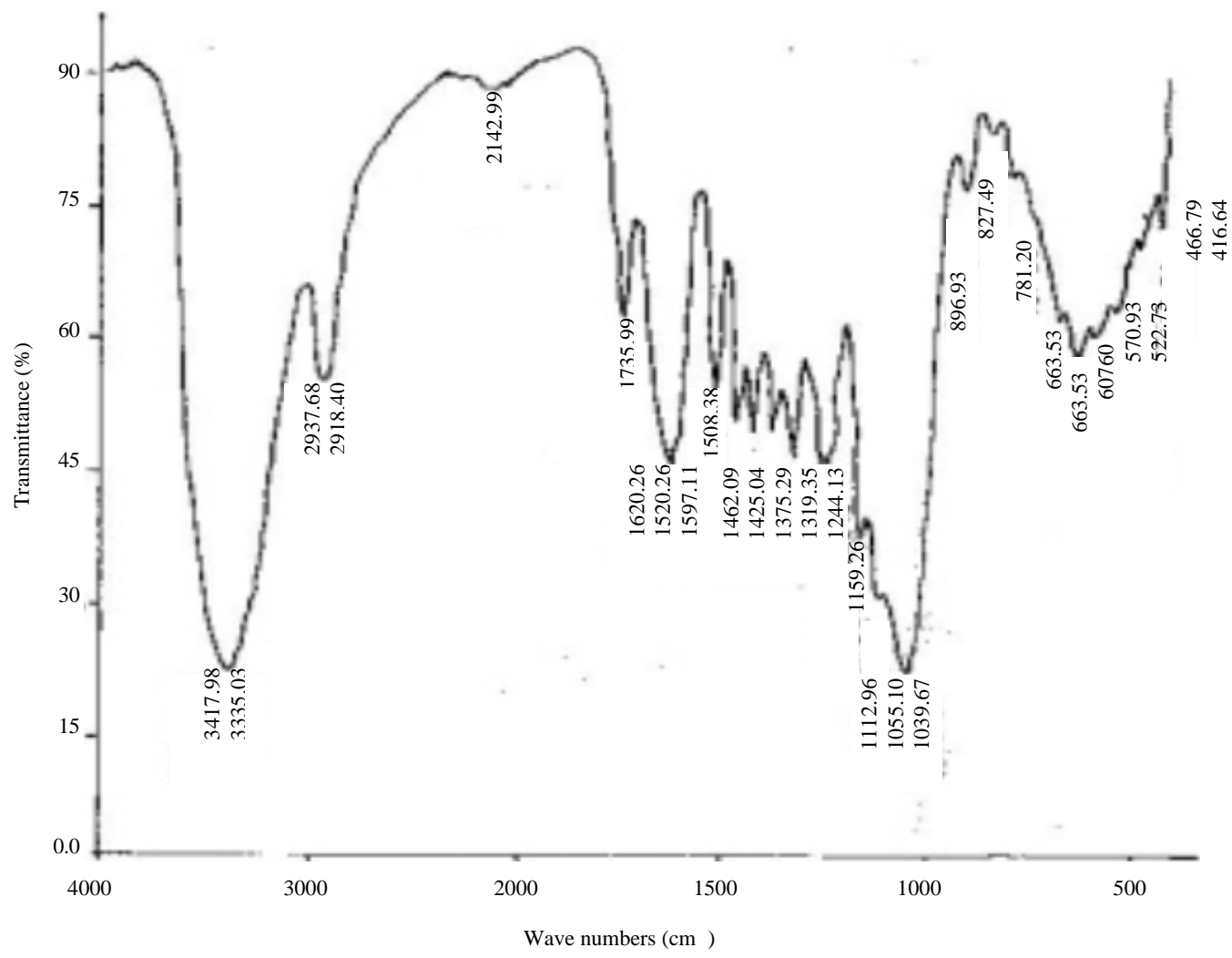

Fig. 2: FTIR spectrum of Sawdust (SD) 

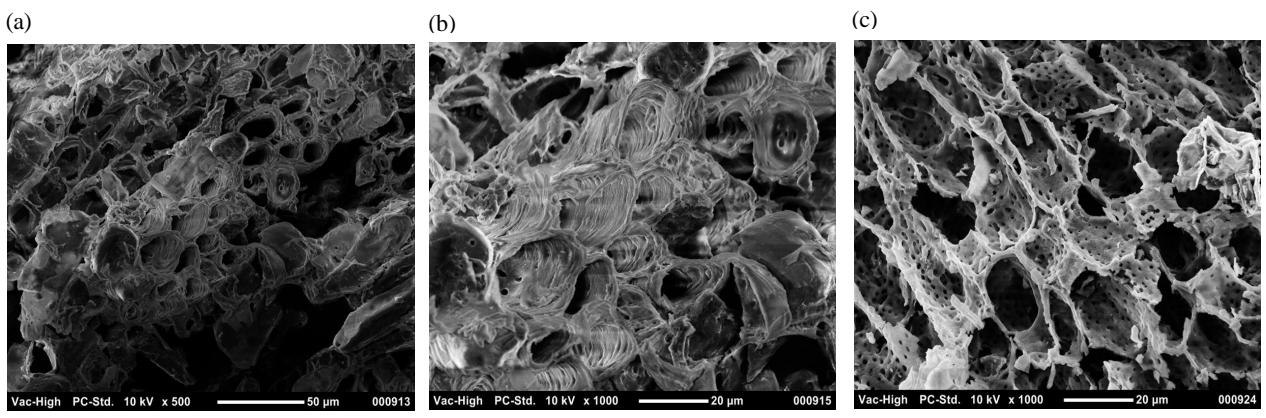

Fig. 3: SEM images of SD at different magnifications: a) $\times 100$; b) $\times 500$ and c) $\times 1000$

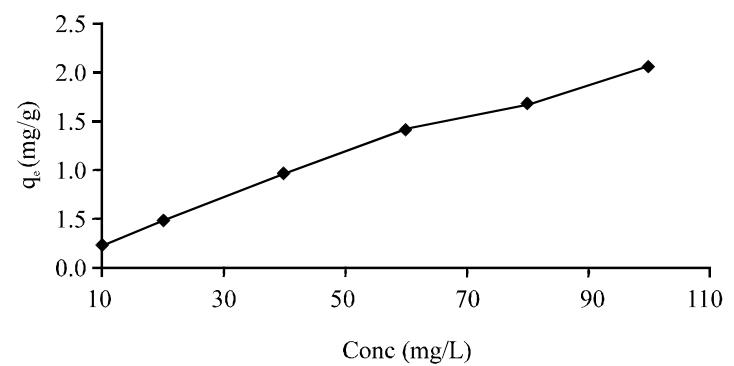

Fig. 4: Effect of initial RB5 concentration on SD adsorption

observation where increasing initial concentration of sorbate resulted in increased adsorption capacity has been reported in the literature (Handan, 2011). The increase in the initial concentration of the dye enhances the interaction between the RB5 dye molecules and the surface of the adsorbent. Also, at low initial concentrations the amount of dye molecules available is low but at higher concentrations the amount available is high enough to overcome the resistance to mass transfer. This was also reported by other researchers.

Effect of SD dose on the adsorption of reactive black 5: Dose of SD was varied from $0.20-1.00 \mathrm{~g}$ in $25 \mathrm{~mL}$ of $50 \mathrm{mg} / \mathrm{L}$ reactive black 5 solution. The adsorption capacity, $\mathrm{q}_{\mathrm{e}}$ that is the mass of reactive black adsorbed by $1 \mathrm{~g}$ of SD decreased with increasing dose of the adsorbent. It reduced from $3.33 \mathrm{mg} / \mathrm{g}$ at $0.1 \mathrm{~g} \mathrm{SD}$ dose to $0.83 \mathrm{mg} / \mathrm{g}$ at a dose of $1.00 \mathrm{~g}$ (Fig. 5). Similar trend was also observed in the adsorption of RB5 on loquat seed (Handan, 2011).

Effect of $\mathbf{p H}$ on RB5 adsorption: The adsorption of RB5 by $\mathrm{SD}$ was studied at various $\mathrm{pH}$ values of the solution (volume $50 \mathrm{~mL}$, concentration $50 \mathrm{mg} / \mathrm{L}$ ) obtained by adding appropriate amounts of $0.1 \mathrm{M} \mathrm{HCl}$ or $0.1 \mathrm{M} \mathrm{NaOH}$. The effect of $\mathrm{pH}$ on $\mathrm{RB} 5$ adsorption arose apparently from the charge properties of both RB5 and SD. It is

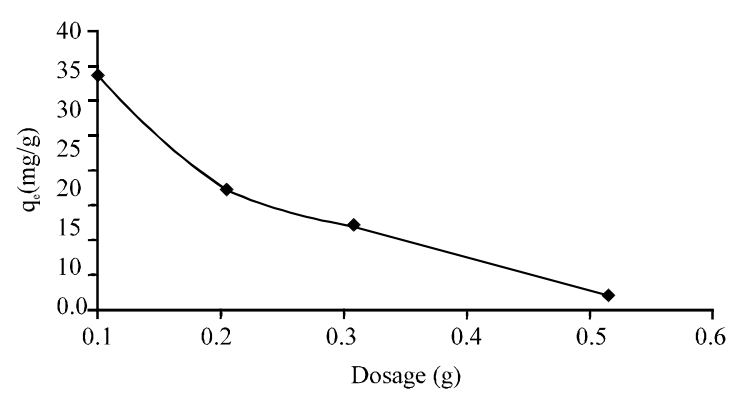

Fig. 5: Effect of SD dose on the adsorption of reactive black 5

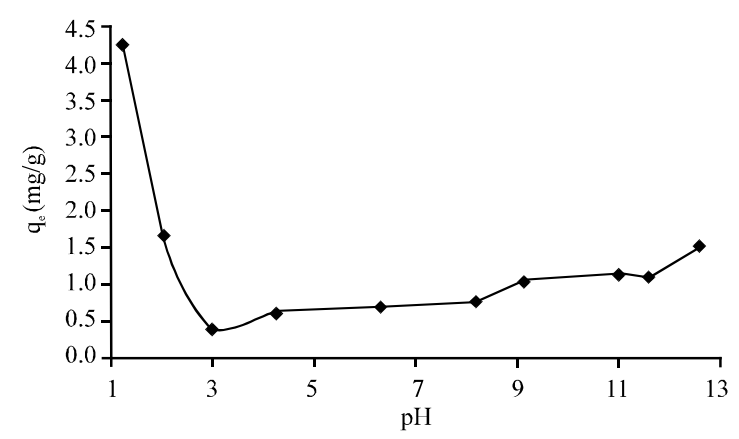

Fig. 6: Effect of $\mathrm{pH}$ on $\mathrm{RB} 5$ adsorption

attraction between the surface of SD and RB5 dye resulting in high adsorption capacity. Low adsorption capacity of RB5 observed at basic $\mathrm{pH}$ is a result of competition between the excess hydroxyl ions and the negatively charged dye ions for the adsorption sites (Iscen et al., 2007). Figure 6 reveals that an increase in $\mathrm{pH}$ from 1-3 decreases RB5 adsorption by SD; The adsorption recognized that the surface of $\mathrm{SD}$ is protonated and acquire a net positive charge with diminishing solution $\mathrm{pH}$. This causes a significantly high electrostatic capacity decreased from $4.4-0.5 \mathrm{mg} / \mathrm{g}$ and then rises gradually at a very slow rate from 4-11. Similar results have been reported in the literature (Iscen et al., 2007, Vijayaraghavan and Yun, 2007). 


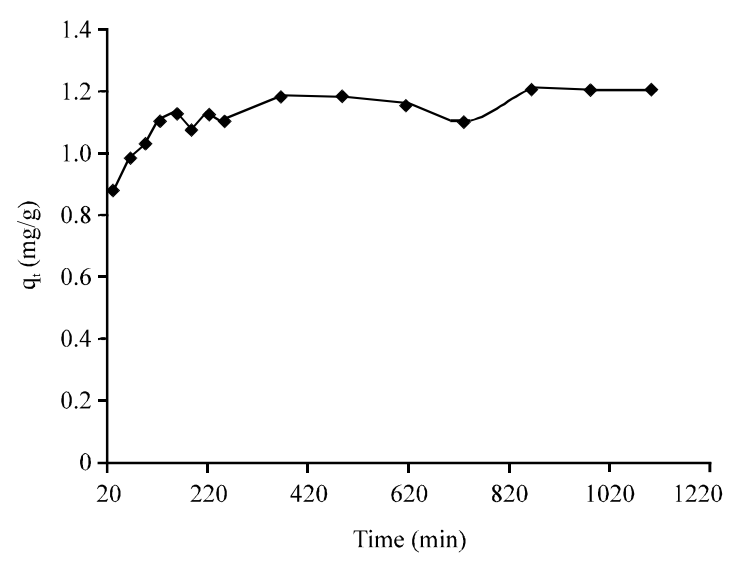

Fig. 7: Effect of contact time on the adsorption of RB5 on $\mathrm{SD}$

Effect of contact time on the adsorption of RB5 on SD: A plot of quantity (qt) adsorbed against time (t) depicts a typical contact time for the removal of RB5 by SD (Fig. 7). The initial rapid phase may be due to the large number of vacant active adsorption sites available at the initial period of the sorption (Wong et al., 2009) this makes the concentration gradient to be high thereby enhancing the sorption process (El-Nemr et al., 2005). The observed initial rapid sorption of the dye can also be connected with ion exchange on the functional groups on the surface of SD (Ho and Ofomaja, 2006). The increase in quantity adsorbed continued at a slower rate until a quasi-static point was reached at about $480 \mathrm{~min}$. This decrease in adsorption rate has been attributed to the reduction in concentration gradient which is the driving force (Vilar et al., 2008) and the gradual uptake of the dye on the inner surface of SD (Ho and Ofomaja, 2006). The enhanced adsorption with increasing contact time can be attributed to the decreasing boundary layer resistance to mass transfer in the bulk solution with time (Horsfall and Abia, 2003).

Kinetics of RB5 adsorption onto SD: The kinetic data was fitted into four models and the kinetic parameters are presented in Table 1. Pseudo-first order model, Pseudo-second order model and Elovich model. Weber-Morris model was also used to know if the diffusion is the only rate determining step.

In the single system in which RB5 only was present, the $\mathrm{R}^{2}$ value for pseudo-first order model, Pseudo-second order model and Elovich model were $0.368,0.998$ and 0.806 respectively. From the $\mathrm{R}^{2}$ value, the kinetics followed pseudo-second order model. The low value of SSE $\left(9.04 \times 10^{-4}\right)$ for this model confirmed the findings. In the binary system in which RB5 was adsorbed in the presence of $5 \mathrm{ppm} \mathrm{CR}$, the high $\mathrm{R}^{2}$ value of pseudo-second order
Table 1: Comparison of rate constants and other parameters for various kinetic models for RB5 in single and binary systems

\begin{tabular}{|c|c|c|c|}
\hline Parameters & $\mathrm{R} \times \mathrm{B} 5$ & Adsorbate system & Values \\
\hline & RB5 only & RB5+5CR & $\mathrm{RB5}+10 \mathrm{CR}$ \\
\hline $\mathrm{q}_{\mathrm{e}}(\mathrm{expt})$ & 1.20 & 1.19 & 1.15 \\
\hline \multicolumn{4}{|c|}{ Pseudo-first order } \\
\hline $\mathrm{R}^{2}$ & 0.368 & 0.914 & 0.882 \\
\hline $\mathrm{K}_{1}$ & $2.07 \times 10^{-3}$ & $3.45 \times 10^{-3}$ & $3.45 \times 10^{-3}$ \\
\hline $\mathrm{q}_{\mathrm{e}}(\mathrm{cal})$ & 0.159 & 0.245 & 0.252 \\
\hline SSE (\%) & 0.30 & 0.27 & 0.25 \\
\hline \multicolumn{4}{|c|}{ Pseudo-second order } \\
\hline $\mathrm{R}^{2}$ & 0.998 & 0.999 & 0.999 \\
\hline $\mathrm{K}_{2}$ & $5.06 \times 10^{-2}$ & $3.98 \times 10^{-2}$ & $3.70 \times 10^{-2}$ \\
\hline $\mathrm{q}_{\mathrm{e}}(\mathrm{cal})$ & 1.20 & 1.21 & 1.17 \\
\hline $\mathrm{H}$ & 0.0733 & 0.0581 & 0.0506 \\
\hline SSE (\%) & $9.04 \times 10^{4}$ & $2.14 \times 10^{-3}$ & $4.96 \times 10^{-3}$ \\
\hline \multicolumn{4}{|c|}{ Elovich model } \\
\hline $\mathrm{R}^{2}$ & 0.806 & 0.953 & 0.916 \\
\hline A & 33.04 & 18.57 & 10.79 \\
\hline $\mathrm{B}$ & 13.18 & 11.71 & 10.79 \\
\hline SSE(\%) & 0.0588 & 0.0397 & 0.0185 \\
\hline \multicolumn{4}{|c|}{ Morris-weber } \\
\hline $\mathrm{R}^{2}$ & 0.653 & 0.843 & 0.813 \\
\hline $\mathrm{K}_{\mathrm{id}}$ & 0.0083 & 0.0098 & 0.0106 \\
\hline $\mathrm{X}_{\mathrm{i}}$ & 0.955 & 0.910 & 0.846 \\
\hline SSE (\%) & 0.078 & 3.98 & 0.333 \\
\hline
\end{tabular}

Table 2: Isotherm model parameters for adsorption of RB5 onto SD

\begin{tabular}{lccc}
\hline Model/Parameters & RB5 only & $\begin{array}{c}\text { RB5+5 ppm } \\
\text { congo red }\end{array}$ & $\begin{array}{c}\text { RB5+10 ppm } \\
\text { congo red }\end{array}$ \\
Langmuir & 0.959 & 0.981 & 0.949 \\
$\mathrm{R}^{2}$ & 2.280 & 2.290 & 2.720 \\
$\mathrm{Q}_{\mathrm{m}}$ & 0.310 & 0.330 & 0.230 \\
$\mathrm{~K}_{\mathrm{a}}$ & & & \\
Freundlich & 0.815 & 0.763 & 0.879 \\
$\mathrm{R}^{2}$ & 0.513 & 0.423 & 0.613 \\
$1 / \mathrm{n}$ & 0.518 & 0.641 & 0.491 \\
$\mathrm{~K}_{\mathrm{f}}$ & & & \\
Temkin & 0.951 & 0.904 & 0.959 \\
$\mathrm{R}^{2}$ & 0.466 & 0.488 & 0.559 \\
$\beta$ & 3.89 & 3.60 & 2.920 \\
$\mathrm{~K}_{\mathrm{T}}$ & & & \\
$\mathrm{D}-\mathrm{R}$ & 0.948 & 0.932 & 0.872 \\
$\mathrm{R} 2$ & $3 \times 10^{7}$ & $6 \times 10^{-7}$ & $3 \times 10^{-7}$ \\
$\beta$ & 1.739 & 1.923 & 1.587 \\
Xm & & & \\
Harkin-Jura & 0.427 & 0.421 & 0.570 \\
$\mathrm{R}^{2}$ & 0.137 & 0.414 & 0.108 \\
$\mathrm{~A}$ & 1.029 & 1.173 & 0.879 \\
$\mathrm{~B}$ & & &
\end{tabular}

model (0.999) makes it the best fit for the kinetics process. The value of SSE which is the lowest for all the models Table 1 further supports these findings.

In the binary system in which RB5 was adsorbed in the presence of $10 \mathrm{ppm} \mathrm{CR}$, the kinetics followed the same trend as that of the first binary system whereby it followed the pseudo-second order model as evident from the high $\mathrm{R}^{2}$ value and low SSE value Table 1. In all the systems, the diffusion is not the only rate determining step in the process. Similar results were obtained in literature (Iscen et al., 2007 and Handan, 2011).

Isotherm of RB5 adsorption onto SD: The 5 different models of isotherm were used to explain the adsorption of RB5 onto SD in single and binary systems. The equilibrium data were fitted into five models and the isotherm parameters are presented in Table 2 . 
Res. J. Applied Sci., 13 (12): 704-710, 2018

Table 3: Thermodynamics parameters for the adsorption of reactive black 5 in single and binary systems on SD

\begin{tabular}{|c|c|c|c|c|c|c|c|c|c|}
\hline \multirow[b]{2}{*}{ Temp (K) } & \multicolumn{3}{|c|}{ Single system (RB5 only) } & \multicolumn{3}{|c|}{ Binary system (RB5+5 CR) } & \multicolumn{3}{|c|}{ Binary system (RB5+10 CR) } \\
\hline & $\begin{array}{l}\Delta \mathrm{G} \\
(\mathrm{kJ} / \mathrm{mol})\end{array}$ & $\begin{array}{l}\Delta \mathrm{H} \\
(\mathrm{kJ} / \mathrm{mol})\end{array}$ & $\begin{array}{l}\Delta \mathrm{S} \\
(\mathrm{J} / \mathrm{mol} . \mathrm{K})\end{array}$ & $\begin{array}{l}\Delta \mathrm{G} \\
(\mathrm{kJ} / \mathrm{mol})\end{array}$ & $\begin{array}{l}\Delta \mathrm{H} \\
(\mathrm{kJ} / \mathrm{mol})\end{array}$ & $\begin{array}{l}\Delta \mathrm{S} \\
(\mathrm{J} / \mathrm{mol} . \mathrm{K})\end{array}$ & $\begin{array}{l}\Delta \mathrm{G} \\
(\mathrm{kJ} / \mathrm{mol})\end{array}$ & $\begin{array}{l}\Delta \mathrm{H} \\
(\mathrm{kJ} / \mathrm{mol})\end{array}$ & $\begin{array}{l}\Delta \mathrm{S} \\
(\mathrm{J} / \mathrm{mol} . \mathrm{K})\end{array}$ \\
\hline 303 & -0.15 & & & -2.04 & -0.15 & & & & \\
\hline 313 & -2.11 & +39.10 & +0.13 & -3.49 & -50.44 & +0.17 & -1.38 & -30.59 & +0.10 \\
\hline 323 & -2.81 & & & -5.51 & & & -2.28 & & \\
\hline
\end{tabular}

In the single system, the Langmuir Model described the equilibrium data best having a high $\mathrm{R}^{2}$ of 0.959 as opposed to that of Temkin (0.951) Dubinin-Radush Kevich (0.948) Freundlich (0.815) and Harkin-Jura (0.427). Also, in the binary system in which RB5 was adsorbed in the presesnce of 5 ppm congo red, the Langmuir Model gave the best fit as evidently seen from the high $\mathrm{R}^{2}$ (0.981).

The order of fitness of the other 4 models is: Dubinin-Radush Kevich >Temkin >Freundlich $>$ Harkin-Jura. But for the adsorption of RB5 in binary system in which RB5 was adsorbed in the presence of 10 ppm CR, Temkin gave the best fit having an high $\mathrm{R}^{2}$ of 0.959 followed by Langmuir $\left(\mathrm{R}^{2}=0.99\right)$ Freundlich $\left(\mathrm{R}^{2}=0.879\right)$ Dubinin-Radush Kevich $\left(\mathrm{R}^{2}=0.870\right)$ and Harkin-Jura $\left(\mathrm{R}^{2}=0.570\right)$. On the overall, Langmuir seems to explain the adsorption on the 2 systems (single and binary) proposing that the adsorption of RB5 onto SD may be physisorption and monolayer. Similar reports was observed in literature (Vijayaraghavan and Yun, 2007).

Thermodynamics of adsorption of RB5 onto SD: A plot of $\ln \mathrm{K}_{\mathrm{C}}$ versus $1 / \mathrm{T}$ for the adsorption of RB5 onto SD for all the systems and the thermodynamic parameters $(\Delta \mathrm{G}, \Delta \mathrm{H}$ and $\Delta \mathrm{S}$ ) are shown in Table 3 . In the single system, $\Delta \mathrm{G}$ is negative indicating the feasibility and spontaneity of the adsorption process at low temperatures. $\Delta \mathrm{H}$ is positive showing that the process is endothermic and heat can be applied to speed up the rate of the reaction and $\Delta \mathrm{S}$ is positive indicating good affinity between RB5 and SD and that there is increased randomness in the sorption process on the surface of SD. But in the binary system whereby RB5 was adsorbed in the presence of 5 ppm CR, although the process was feasible as seen from the $\Delta \mathrm{G}$ being negative but the process was exothermic judging from the fact that $\Delta \mathrm{H}$ is negative and the $\Delta \mathrm{S}$ is positive like that of the single system. This implies that in the presence of another adsorbate, heat might not be needed to speed up the rate of reaction. The binary system of RB5 in the presence of $10 \mathrm{ppm}$ congo red followed the same trend as that of the previous binary system.

\section{CONCLUSION}

The study investigated the potential of sawdust, a well-known waste in agroforestry for removing Reactive Black 5 (RB5) from aqueous solution in single and binary systems.
The equilibrium time for the sorption of RB5 was $840 \mathrm{~min}$ and the optimum dose was $0.800 \mathrm{G}$. The kinetics of the adsorption of RB5 in both systems could best be described by the pseudo-sec order model.

Temkin, Dubinin-Radushkevich and Freundlich isotherms had high coefficients of determination than that of Harkin-Jura isotherm but it seems Langmuir explained RB5 isotherm better as evidently seen from its higher regression coefficient. Thermodynamically, the sorption of RB5 is feasible as well as spontaneous seeing that its $\Delta \mathrm{G}$ is negative. Also, the sorption process is endothermic as its $\Delta \mathrm{H}$ is positive for the single system and one of the binary system but in the binary system comprising of RB5 and $5 \mathrm{ppm}$ congo red, the $\Delta \mathrm{H}$ is negative. In conclusion, raw sawdust is a very potential adsorbent capable of abating the level of dye residue in wastewaters.

\section{REFERENCES}

Akceylan, E., M. Bahadir and M. Yylmaz, 2009. Removal efficiency of a calix [4] arene-based polymer for water-soluble carcinogenic direct azo dyes and aromatic amines. J. Hazard. Mater., 162: 960-966.

Aksu, Z. and S. Tezer, 2000. Equilibrium and kinetic modelling of biosorption of Remazol Black B by Rhizopus arrhizus in a batch system: Effect of temperature. Process Biochem., 36: 431-439.

Demirbas, E., M. Kobya, E. Senturk and T. Ozkan, 2004. Adsorption kinetics for the removal of chromium (VI) from aqueous solutions on the activated carbons prepared from agricultural wastes. Water $\mathrm{Sa}, 30$ : 533-539.

E1 Nemr, A.H.M.E.D., O. Abdelwahab, A.Z.Z.A. Khaled and A.E. Sikaily, 2005. Removal of chrysophenine dye (DY-12) from aqueous solution using dried Ulva lactuca. Egypt. J. Aquat. Res., 31: 86-98.

Eren, Z. and F.N. Acar, 2006. Adsorption of Reactive Black 5 from an aqueous solution: Equilibrium and kinetic studies. Desalination, 194: 1-10.

Handan, U.C.U.N., 2011. Equilibrium, thermodynamic and kinetics of reactive black 5 biosorption on loquat (Eriobotrya japonica) seed. Sci. Res. Essays, 6: 4113-4124. 
Ho, Y.S. and A.E. Ofomaja, 2006. Biosorption thermodynamics of cadmium on coconut copra meal as biosorbent. Biochem. Eng. J., 30: 117-123.

Horsfall, Jr. M. and A.A. Abia, 2003. Sorption of cadmium (II) and zinc (II) ions from aqueous solutions by cassava waste biomass (Manihot sculenta Cranz). Water Res., 37: 4913-4923.

Iscen, C.F., I. Kiran and S. Ilhan, 2007. Biosorption of Reactive Black 5 dye by Penicillium restrictum: The kinetic study. J. Hazard. Mater., 143: 335-340.

Rachakornkij, M., S. Ruangchuay and S. Teachakulwiroj, 2004. Removal of reactive dyes from aqueous solution using bagasse fly ash. Songklanakarin J. Sci. Technol., 26: 13-24.
Seey, T.L. and M.J.N.M. Kassim, 2012. Acidic and basic dyes removal by adsorption on chemically treated mangrove barks. Intl. J. Appl. Sci. Technol., 2: 270-276.

Vijayaraghavan, K. and Y.S. Yun, 2007. Utilization of fermentation waste (Corynebacterium glutamicum) for biosorption of reactive black 5 from aqueous solution. J. Hazard. Mater., 141: 45-52.

Vilar, V.J., C.M. Botelho and R.A. Boaventura, 2008. Copper removal by algae Gelidium, agar extraction algal waste and granulated algal waste: Kinetics and equilibrium. Bioresour. Technol., 99: 750-762.

Wong, S.Y., Y.P. Tan, A.H. Abdullah and S.T. Ong, 2009. The removal of basic and reactive dyes using quartenised sugar cane bagasse. J. Phys. Sci., 20: 59-74. 